\title{
Dimensión simbólica del arte y politicidad juvenil: análisis de una intervención artística en el marco de una acción colectiva de protesta
}

\section{Symbolic dimension of youth art and politicization: analysis of an artistic intervention within the framework of an act of collective protest}

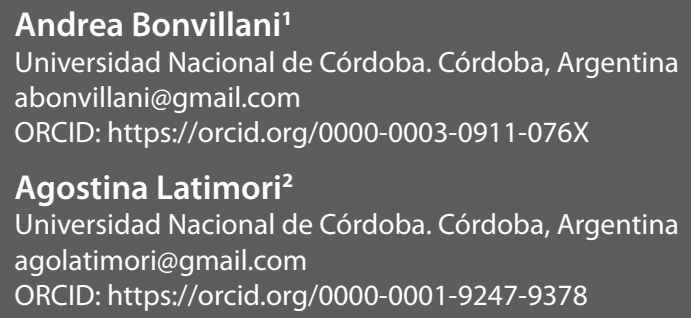

Citar como: Bonvillani, A. y Latimori, A. (2021). Dimensión simbólica del arte y politicidad juvenil: análisis de una intervención artística en el marco de una acción colectiva de protesta. Desde el Sur, 13(1), e0006

\section{RESUMEN}

El objetivo del artículo es reflexionar sobre el efecto político del arte al interior de una acción colectiva de protesta antirrepresiva, impulsada por jóvenes de la ciudad de Córdoba (Argentina). Focalizando en el análisis de una intervención artística específica y en el marco de un diseño cualitativo, las técnicas de construcción de datos implementadas fueron: conversaciones en marcha (en el sentido de Bonvillani), observación participante y entrevistas en profundidad. Se concluye que el arte, uno de los modos de cursar la politicidad juvenil en la actualidad, permite rebasar los límites de significación que impone la racionalidad discursiva, abriendo a una multiplicidad de

1 Doctora en Psicología por la Universidad Nacional de Córdoba. Directora del Proyecto de investigación «Militancias juveniles cordobesas», radicada en el Instituto de Investigaciones Psicológicas (Conicet) de la Facultad de Psicología de la Universidad Nacional de Córdoba (UNC).

2 Licenciada en Psicología por la Universidad Nacional de Córdoba. Integrante del Proyecto de investigación «Militancias juveniles cordobesas», bajo la dirección de Andrea Bonvillani, radicada en el Instituto de Investigaciones Psicológicas (Conicet) de la Facultad de Psicología de la Universidad Nacional de Córdoba (UNC). 
sentidos ligados a lo sensorial-corporal y lo imaginativo. En eseaspecto radica su potencialidad política:la disrupción de tiempos/espacios/sentidos instituidos hegemónicamente posibilita una nueva distribución en la partición de lo sensible, locus de la política en términos rancerianos.

\section{PALABRAS CLAVES}

Arte, política, símbolo, juventud

\section{ABSTRACT}

The aim of this article is to reflect on the political effect of art within a collective act of anti-repressive protest, spearheaded by young people in the city of Cordoba (Argentina). Focusing on the analysis of a specific artistic intervention and within the framework of a qualitative design, the data construction techniques implemented were: ongoing conversations, participatory observation, and in-depth interviews. It is concluded that art, currently one of the methods of youth politicization, makes it possible to go beyond the limits of meaning imposed by discursive rationality, opening up a multiplicity of senses associated with the sensorial-corporal and the imaginative. It is here that its political potential resides: the disruption of hegemonic times/spaces/senses makes possible a new distribution in the partition of the sensorial, the locus of politics in Rancierian terms.

\section{KEYWORDS}

art, politics, symbol, youth

\section{Introducción}

Durante los últimos años se fue produciendo una multiplicación y diversificación de los modos de poner en visibilidad las demandas al capitalismo avanzado en el espacio público. En América Latina, en consonancia con el plano internacional, se produce a partir de la década de 1980 un pasaje hacia los denominados «nuevos movimientos sociales» (Diani, 2015), que pusieron de relieve la aparición de un amplio espectro de actores y modalidades de acción colectiva. Los nuevos movimientos sociales latinoamericanos se caracterizaron, en palabras de Svampa (2007), por una acción defensiva y un discurso antineoliberal, así como también por la construcción de repertorios de confrontación diversos, en los que prevalece la acción directa, no convencional y disruptiva, con un carácter autoafirmativo y de construcción horizontal, dejando de lado 
acciones instrumentales tradicionales, como por ejemplo la huelga. Estas características están presentes de manera particularmente evidente en las formas de politicidad de las juventudes en la contemporaneidad. Como sostiene Vommaro (2015), al interior de los procesos políticos actuales, los jóvenes adquieren un rol protagónico, al construir nuevas modalidades de hacerse oír y visibilizar sus necesidades, dinamizar la conflictiva social, cuestionar ordenamientos establecidos desde matrices hegemónicas y reclamar la incorporación de sus demandas en la configuración de la agenda pública de las sociedades contemporáneas

En ese marco, intervenir el espacio urbano a través del arte, como acción política de protesta, se destaca como una forma de participación política juvenil que pone en juego diversos canales expresivos y organizativos que no se encuentran anclados en la institucionalidad política tradicional (Bonvillani, 2020a).

En la ciudad de Córdoba (Argentina), una expresión importante de politización juvenil es la Marcha de la Gorra (en adelante, MDG) que se realiza ininterrumpidamente desde 2007 . Constituye una manifestación multitudinaria que convoca especialmente a jóvenes, con el objetivo principal de reclamar por la derogación del actual Código de Convivencia ${ }^{3}$, visibilizando la persecución y abuso policial, que tiene como blanco central a jóvenes de sectores populares, que llega en casos extremos a su asesinato a manos de las fuerzas de seguridad local (Bonvillani, 2020b). Esta forma modular clásica de acción colectiva de protesta (Bonvillani y Roldán, 2017) forma parte de un intenso movimiento antirrepresivo local que se articula en contra de las políticas de seguridad ciudadana impuestas desde el aparato político-policial-represivo provincial (Job, 2018).

Desde un punto de vista estético, la MDG se caracteriza por la puesta en juego de un repertorio de confrontación amplio y variado, con una fuerte presencia de recursos expresivos, en el que se destaca un modo de intervenir la calle a través del arte; los cuerpos serían el locus de realización preferente (Bonvillani y Roldán, 2017).

El objetivo de este artículo ${ }^{4}$ es reflexionar sobre el efecto político del arte, particularmente en su dimensión simbólica, al interior de una acción

3 El Código de Convivencia (ex Código de Faltas, modificado y en vigencia desde 2015) es la normativa que regula específicamente las contravenciones en el ámbito provincial cordobés; es decir, legisla sobre aquellas conductas que se pueden tipificar como delitos menores no alcanzables por el Código Penal y que, generalmente, se producen en la vía pública (Lerchundi y Bonvillani, 2016).

4 Se desprende de un trabajo de investigación más amplio, realizado por Agostina Latimori para obtener el título de grado de la licenciatura en Psicología de la Universidad Nacional de Córdoba, dirigido por Andrea Bonvillani, en colaboración con Gabriela Maorenzic y Paula Belén Mallea. 
colectiva de protesta antirrepresiva, impulsada por jóvenes cordobeses. Para ello se hará foco en el análisis de una intervención específica, llevada a cabo en la decimoprimera edición de la MDG en 2017, entendiendo que la consideración de la dimensión expresiva y estética en el campo de los movimientos sociales, a través del análisis de las intervenciones artísticas, permite comprender con mayor profundidad aquellos lenguajes que los sujetos ponen en juego en la arena pública, al aportar a la indagación sobre los diversos modos de cursar la politicidad por parte de los jóvenes en la actualidad.

\section{Intervenciones artísticas, estética y política: el caso de la MDG}

La deshumanización impuesta por el neoliberalismo y su modelo de exclusión y control social afectaron a gran parte de Latinoamérica, lo cual dio lugar a la construcción de estrategias estéticas de resistencia que en las últimas décadas reinstalaron al arte en el escenario urbano (Ortega, 2015). Así, los movimientos sociales latinoamericanos presentan repertorios de movilización ligados a la expresividad y la performatividad, lo que implica una puesta en marcha de prácticas culturales y artísticas como formas de confrontación y posicionamiento político (Scribano y Cabral, 2009) que encuentran en la calle su escenario de dramatización ${ }^{5}$.

Según Longoni (2010), las prácticas de articulación entre producción artística y acción política tienen una larga y vasta historia en Latinoamérica, y particularmente en Argentina. La categoría activismo artístico refiere a aquellas producciones y acciones, a menudo colectivas, que se sirven de recursos artísticos para tomar posición e incidir de alguna forma en el territorio de lo político (Longoni, 2010). Estas iniciativas colectivas avanzan en pensar la reformulación del estatuto de lo artístico en relación con la crisis de legitimidad de las viejas formas de la representación, tanto de la política como del arte. Además, se proponen (auto)analizar los modos en que sus prácticas artísticas entran en relación con los movimientos sociales, y debaten acerca de estrategias horizontales de organización colectiva, y de la construcción de formas alternativas de acción e incidencia sobre la agenda pública.

El activismo artístico puede entenderse entonces como una praxis puesta al servicio de las luchas contra situaciones de injusticia social, las cuales se despliegan no solo en un plano material, sino también simbólico.

$5 \mathrm{Si}$ bien es posible reconocer puntos de contacto entre la propuesta analítica aquí formulada y las reflexiones en torno a la performatividad y performance callejera latinoamericana, su consideración de manera profunda excede los límites de este trabajo, que pueden ser retomados en el futuro a partir de la sugerencia del revisor del artículo, a quien agradecemos. 
Este término alude aquí a la producción incesante de sentidos a partir de la cual los seres humanos elaboramos nuestras interpretaciones sobre nosotros mismos, sobre los otros y sobre el mundo. Los sistemas simbólicos estructuran y organizan las relaciones humanas y frecuentemente son manipulados por la cultura dominante para naturalizar arbitrariamente aspectos que refuercen y perpetúen su poder (Escobar, 2021).

En el caso de la MDG, esta se constituye en un escenario para la disputa por el poder simbólico, a través de un trabajo político de impugnación de las representaciones hegemónicas que circulan en torno a la equivalencia simbólica joven pobre = peligroso (Bonvillani, 2015a). Dichas representaciones se constituyen en la práctica en un prejuicio por medio del cual se estigmatiza a grupos de jóvenes de sectores populares y se justifica su persecución sistemática a manos de la Policía. Para estos actores sociales, el rechazo de estas imágenes que los desacreditan, así como la creación colectiva de significaciones contraculturales, es un claro ejercicio de politicidad (Bonvillani, 2020a).

En el marco de este trabajo, las intervenciones artísticas se entienden como cualquier puesta en escena en el espacio público, sea individual o colectiva, donde se emplean diversos recursos y prácticas expresivas que remiten al campo del arte en un sentido amplio. "Artísticas» remite al uso de recursos discursivos y extradiscursivos, mientras que «intervenir», proveniente del latín intervenire, significa «venir entre». Así, hablar de intervenciones artísticas alude a un entrevenirlacalle, enfatizando el sentido disruptivo, provocador, con el que el arte se presenta en el espacio público. En síntesis, las intervenciones artísticas en una acción colectiva de protesta constituyen una forma de organización de los sentidos que configura una determinada estética, al mismo tiempo que una práctica política, en tanto expresan formas de estar con otros, de organizar espacios y modos de interacción poniendo en visibilidad demandas, conflictos y luchas sociales a través de una dimensión estético-cultural (Gabrieloni y Bonvillani, 2015).

El análisis de las intervenciones artísticas como formas de politicidad juvenil se enmarca en las relaciones entre estética y política. Rancière (2007) entiende a lo político como un topos donde tiene lugar un desacuerdo fundamental entre dos procesos heterogéneos: el de gobierno y el de igualdad; el de la policía y la política, respectivamente. El proceso del gobierno o policía designa los lugares y funciones al interior de una comunidad, a partir de fijar una distribución jerárquica de inclusión y exclusión, dañando el principio de igualdad en el que se funda la política (Rancière, 2000). Esta distribución de nombres y funciones, de espacios y tiempos, constituye lo que él denomina la división de lo sensible (Rancière, 2002). 
La política consiste en reconfigurar la repartición policial de lo sensible, en hacer visible lo que no lo era y en hacer escuchar como hablantes a aquellos que solamente eran percibidos como "animales ruidosos», haciendo que se manifieste la parte de los que no tienen parte dentro del común, verificando la igualdad de cualquiera con cualquiera (Rancière, 2000). Podría pensarse que, desde esta perspectiva, los movimientos sociales y acciones colectivas se hallan del lado de la política cuando buscan hacer emerger aquello invisibilizado en la esfera pública, mostrando el desacuerdo con la distribución ejercida por el orden policial, corriéndose del lugar y la función asignada en esa repartición de lo sensible sostenida en la ficción de una desigualdad construida.

Según Rancière (2010), la política es la práctica que rompe con el orden policial mediante la invención de una instancia de enunciación colectiva que rediseña el espacio de las cosas comunes. En este sentido, la MDG se presenta en sí misma como un acto disruptivo, ya que se trata de cuerpos cuya presencia, indeseada en el espacio público, irrumpe materialmente e impugna sentidos hegemónicos. La aparición polémica de estas presencias rechazadas pone en evidencia la ausencia de fundamentos en el reparto del común, en la medida en que manifiesta como posibles otros modos de componer y repartir el mundo sensible $y$, por lo tanto, otras formas de hacer visible la vida política de la comunidad, y se constituye en una práctica de verificación de igualdad.

Teniendo en cuenta que la estética no es simplemente una especificidad del mundo del arte, sino que es una experiencia sensorial que participa en la definición de lo común, este trabajo de creación de disensos constituye una estética política Rancière (2005) ${ }^{6}$. Por lo tanto, arte y política están profundamente vinculados, no porque el arte traslade sus criterios estéticos a la política, sino por la distancia que ambas guardan en relación con las identidades, las funciones y los lugares designados por la división policial de lo sensible.

La estética de la política constituye un modo de recomposición del orden social situado sobre una distorsión, al poner en cuestión, a partir de nuevas formas, la división policial de lo sensible, y habilitar, en ocasiones, reparticiones inéditas que posibilitan una reconfiguración simbólica y material que trastoca las distribuciones anteriores (Rancière, 2005). Lo político, entonces, es una condición inherente al arte mismo

6 Es necesario diferenciar este planteo del de Benjamin cuando designa «estetización de la política» a la puesta en escena del poder y de la movilización de masas propias del fascismo, es decir, como una mera forma expresiva sin potencial transformador, con un efecto más bien encubridor y adormecedor (Gabrieloni y Bonvillani, 2015). 
en su experimentación, en su vivencialidad en tanto creador de disenso. En palabras del autor: «las prácticas artísticas son maneras de hacer, que intervienen en la distribución general de las maneras de hacer y en sus relaciones con las maneras de ser y las formas de su visibilidad» (Rancière, 2002, p. 3).

\section{Estrategia metodológica}

El trabajo de campo cuyos resultados se presentan en este artículo se realizó en 2017 en el marco de la decimoprimera edición de la MDG, desde una aproximación etnográfica inspirada en la etnografía de eventos (Borges, 2004), que recrea el «estar ahí» propio de la etnografía, en tensión con las particularidades de una manifestación callejera, es decir, la complejidad de los procesos de organización implicados, la pluralidad de actores participantes y el carácter de acción fugaz en el tiempo y acotada en el espacio público (Bonvillani, 2018). De acuerdo con los objetivos específicos de la investigación que origina este artículo, de todas las dimensiones analíticas concernidas en la MDG como objeto de estudio, el interés estuvo centrado en las intervenciones artísticas que allí se desplegaron.

En el marco de la etnografía realizada, las técnicas de construcción de datos fueron tres: conversaciones en marcha (Bonvillani, 2018), observación participante (Guber, 2001) y entrevistas en profundidad (Valles, 2007).

Las conversaciones en marcha se plantean en el propio curso del estarahí-etnográfico, prescindiendo por ello de la fijación de un encuadre previo. Por ende, fueron encuentros casuales y espontáneos tanto con participantes de intervenciones artísticas como con manifestantes que no participaban de ellas. Su desarrollo se enmarcó en las coordenadas témporo/espaciales de la manifestación, y la acompañaron sin detener su ritmo. Para ello se realizaron breves grabaciones de audio in situ en reemplazo del típico registro escrito en cuaderno de campo, lo cual posibilitó plasmar de manera más rápida y fluida las sensaciones, sentimientos, impresiones y pensamientos que los manifestantes compartían con las investigadoras al calor del evento. El trabajo de campo en calle se completó con la toma de fotografías y filmaciones que luego se enriquecieron mediante la recopilación de imágenes de acceso público compartidas en redes sociales por distintas organizaciones que participan de la MDG.

La MDG se desarrolla en un espacio/tiempo que desborda el mero hecho manifestante en las calles céntricas de la ciudad un día determinado del año, ya que se realizan reuniones previas de organización y posteriores 
de evaluación. Estas actividades están a cargo de la mesa organizadora, integrada por distintos agrupamientos sociales, culturales, estudiantiles, políticos, etc., que deciden de manera democrática el para qué y el cómo de la acción colectiva año tras año (Bonvillani, 2018), por medio de comisiones temáticas y de instancias plenarias. Una de estas comisiones es la que se ocupa de las intervenciones artísticas, la cual recibió especial atención durante el desarrollo de la observación y el registro etnográficos, de acuerdo con los objetivos de la investigación. También se realizó trabajo de campo en los eventos y las actividades culturales que se hacen previamente en barrios y en el centro de la ciudad de Córdoba, con el objetivo de difundir la propuesta y convocar a la participación.

Dadas las dificultades de establecer un diálogo extenso y reflexivo con quienes están interviniendo en el aquí y ahora de la acción colectiva, así como la necesidad de evitar obstaculizar su dinámica, se tomaron $10^{7}$ entrevistas abiertas y en profundidad, basadas en un guion (Valles, 2007) y a posteriori de la edición 2017 de la MDG. Dicho guion de temas tuvo como eje las construcciones de sentido acerca de las intervenciones artísticas realizadas en forma específica en la edición de la MDG bajo estudio. El muestreo fue el denominado «basado en criterios ${ }^{8}$ » (Maxwell, 1996), a los fines de lograr una cierta representatividad o tipicidad de los sujetos, escenarios y actividades seleccionadas, sin perjuicio de atender a la heterogeneidad del caso.

La cuestión del género de los participantes fue objeto de reflexión durante el desarrollo del trabajo que origina este artículo, en el sentido de cómo proceder metodológicamente para no eludir dicha cuestión sin caer en atribuciones erróneas basadas en asociaciones de sexo-género propias de la matriz heteropatriarcal y cis normativa ${ }^{9}$. Por ejemplo, el género autopercibido no fue preguntado en el momento de la realización de entrevistas $y$, en consecuencia, decidimos utilizar como referencia en los fragmentos citados las marcas discursivas de género que ellos utilizaban

7 Cabe aclarar que, de este número, solo una de las entrevistadas (nombrada ficticiamente como «Zoe») se vincula de forma directa con la intervención artística que se analiza en este artículo, motivo por el cual los fragmentos de dicha entrevista son más frecuentemente citados.

8 Dichos criterios fueron: modalidades de participación en la MDG (ya sea en la calle, en la mesa organizadora y en los barrios donde se realizaron las actividades culturales); antigüedad en la participación en la acción de protesta; participación en la Comisión Artística en general y en la intervención específica considerada en este artículo; participación inscrita en un grupo, organización o colectivo o en forma individual.

9 Estas inquietudes representan desafíos actuales para la práctica de investigación, desde una perspectiva reflexiva y crítica, y desde una ética basada en un profundo respeto por las maneras como cada sujeto se define a sí mismo, conforme a la Ley 26743 de Identidad de Género sancionada en 2012 en Argentina. 
en sus relatos para referirse a sí mismos, más allá de las impresiones externas ligadas al género expresado.

El número de entrevistados fue determinado por la emergencia de redundancias en las respuestas, es decir, por el criterio de saturación (Maxwell, 1996) propio de los estudios cualitativos. Estos sujetos se contactaron a instancias de su participación en la mesa organizadora, así como in situ durante el trascurso de la marcha.

Una vez que se transcribieron todos los registros de audio de las conversaciones en marcha y de las entrevistas en profundidad y se procedió al ordenamiento y sistematización de las observaciones etnográficas realizadas, se realizó un análisis de tipo cualitativo conducido según los procedimientos de codificación abierta, axial y selectiva de la teoría fundamentada en los hechos (Strauss y Corbin, 2002). A partir de las recurrencias y divergencias encontradas, este ejercicio de análisis e interpretación permitió la construcción de ejes y categorías, las cuales se presentan a continuación.

La forma de citación de los fragmentos que dan respaldo empírico al análisis es la siguiente: nombre ficticio para preservar el anonimato, forma de participación en la acción colectiva, técnica de construcción de dato correspondiente y fecha.

\section{Análisis de la «intervención de los sahúmos»}

La cantidad y diversidad de intervenciones artísticas que se desarrollan hacen que cada edición de la MDG sea una fuente inagotable de la cual brotan una multiplicidad de expresiones, mensajes, sensaciones, emociones y producciones de sentido, que a su vez varían en función de quienes las observan, las vivencian, las hacen cuerpo.

Como se adelantó en la introducción, este trabajo hace foco en una de ellas: la denominada «intervención de los sahúmos» o «de los turíbulos», la cual fue puesta en escena durante la decimoprimera MDG por parte de un grupo de activistas locales. La intervención se caracterizó por ser una construcción colectiva y participativa que posibilitó un cierto grado de preparación previa: algunos activistas coordinaron con anterioridad lineamientos generales referidos a la vestimenta y la coreografía, mientras que otros manifestantes se sumaron de manera espontánea, en el curso de la acción colectiva en la calle.

Desde una aproximación descriptiva, esta intervención consistió en el desplazamiento coreográfico de casi cien personas que fueron recorriendo las calles del centro de la ciudad de acuerdo con el trazado de la MDG, a modo de procesión y sosteniendo en sus manos un objeto 


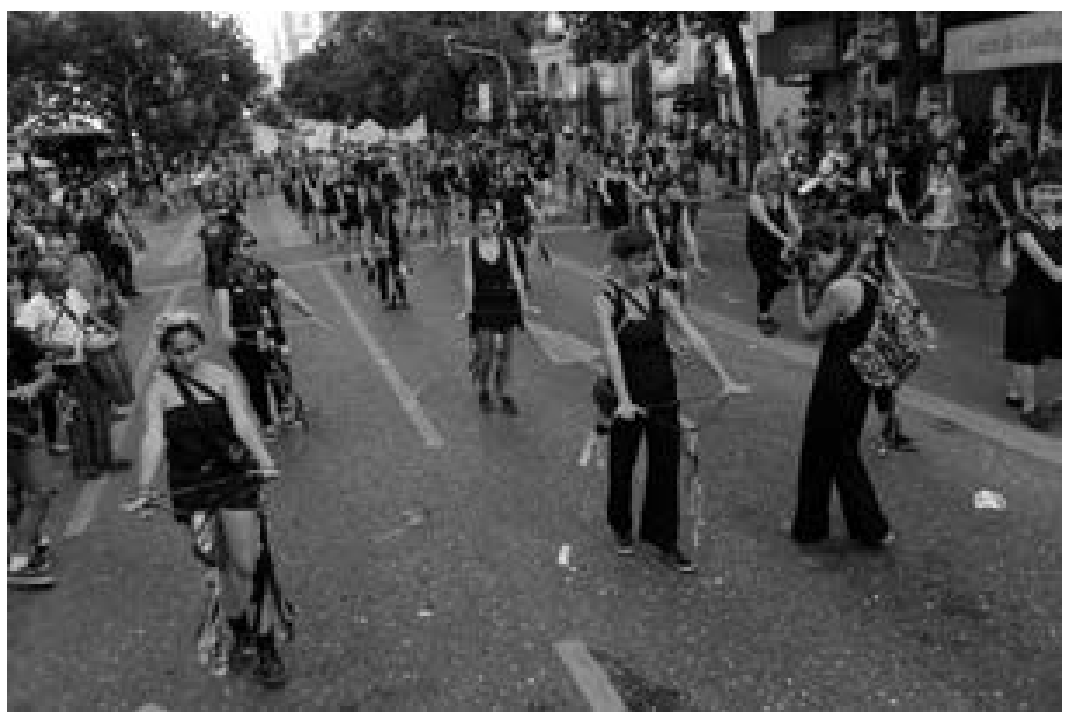

FOTOGRAFÍA 1

Fuente: Página de Facebook «Marcha de la Gorra Córdoba», 2017 (https://www.facebook.com/MarchaDeLaGorraCba/ photos/1780749981969467)

sahumante denominado turíbulo o incensario. Este elemento ${ }^{10}$ consiste en un recipiente de metal con una tapa con un orificio, en cuyo interior, por encima de una fina capa de brasas, se colocan granos de incienso, que tras encenderse liberan un humo sutil y un aroma dulce, agradable y suave. Los participantes iban, en su mayoría, vestidos de negro, con diversos signos y símbolos pintados en sus cuerpos y rostros, salvo aquellos que se integraron en el momento mismo de la marcha.

El desplazamiento de estos cuerpos vestidos de negro, junto con el movimiento pendular de los sahúmos que esparcían olores y un humo grácil, ofrecieron una diversidad de experiencias sensoriales, desde múltiples registros: visual, olfativo, auditivo, entre otros, que dejaba en actitud de perplejidad a quienes se detenían a observar, e invitaban a ahondar en lo que le sucede al propio cuerpo en el aquí y ahora de la calle, y buceaban en las afectaciones mutuas que devienen de las diversas estimulaciones sensoriales.

La «intervención de los sahúmos» constituyó una invitación a un ambivalente juego entre misterio y revelación, entre lo sagrado y lo profano, lo luminoso y lo oscuro, creando un clima emocional difuso

10 Los turíbulos fueron confeccionados de manera casera, tras reciclar latas vacías de cerveza, tiras de colores y tapas pequeñas de metal. 
o, incluso, indeterminado, donde las sonrisas, el disfrute y los guiños cómplices de las participantes cedían paso a miradas crudas y firmes, rostros tensos, movimientos angulosos y sonidos intensos (registro etnográfico en la decimoprimera MDG, 20/11/17).

La «intervención de los sahúmos» fue significada como «un ritual cargado de elementos simbólicos» (Augusto, artista y espectador, entrevista del 17/10/18), que, tal como se desarrolla a continuación, remite a múltiples sentidos.

Las prácticas vinculadas con las sustancias aromáticas, en particular el incienso, ocupan un lugar destacado en distintas ceremonias religiosas tanto de Oriente como de Occidente, ya que poseen una connotación espiritual presente en plegarias, súplicas y todo tipo de ritos de comunicación con las divinidades. En el caso de la liturgia católica, el sentido religioso de la quema del incienso estaba dado porque se consideraba que «su aroma agradaba a las divinidades y quien lo ofrecía accedía desde la tierra al estrato divino. Sus ruegos, mimetizados con el humo, ascendían hasta el Dios» (Grau-Dieckmann, 2003, p. 78).

Si bien las intenciones de quienes planificaron y coordinaron la intervención se despegan completamente del catolicismo, la acción de incensar en la MDG se corresponde con los sentidos que la práctica religiosa tiene, en términos de limpieza, purificación y elevación.

Según lo expresado por una de las artistas que organizó la intervención, la propuesta surge, en parte, como respuesta a los efectos que había tenido la última intervención artística planificada por este grupo en agosto de ese año, en una manifestación anterior ${ }^{11}$. Tras los disturbios generados en esa oportunidad y la elaboración exagerada y maliciosa de los medios de comunicación hegemónicos, la intervención en sí y la marcha en la que se realizó adquirieron una connotación negativa vinculada con la violencia que se les suele atribuir a las protestas callejeras juveniles, por lo que fueron descontextualizadas respecto del sentido que sus protagonistas quisieron darle. En las reuniones previas de organización de la decimoprimera edición de la MDG circuló la idea de realizar una intervención artística que estuviese ligada a un sentido

11 La intervención a la que nos referimos consistió en una procesión multitudinaria al interior de otra marcha del campo antirrepresivo de Córdoba, donde quienes participaban portaban antorchas encendidas. Según el relato de una de las coordinadoras, la idea es tomada de la imagen de procesiones religiosas donde sus participantes portan velas en representación de las almas bendecidas de personas difuntas. El uso de antorchas en lugar de velas responde a la intención de enfatizar y amplificar la importancia de reivindicar la vida de los jóvenes y honrar su alma: «viste que siempre cuando se muere alguien hacen estas marchas como con el fueguito, era como que las almas de estos pibes no eran unas velitas sino altas antorchas» (Zoe, coordinadora de la «intervención de los sahúmos», entrevista del 26/9/18). 
de limpieza y purificación: se esperaba que el humo limpiara las energías negativas y calmara los impulsos agresivos, que se habían visto avivados por el recrudecimiento de las políticas represivas del gobierno provincial en los últimos años ${ }^{12}$ (registro etnográfico de la mesa organizadora, 12/10/17).

Como ya se ha expresado, pensar al espacio público como territorio de disputas simbólicas implica la necesidad de producir un contradiscurso, a través de diversos lenguajes. En este caso, el lenguaje del arte permitió impugnar los sentidos hegemónicos producidos particularmente por los medios de comunicación locales en torno a las juventudes de sectores populares que se manifiestan en la MDG, matizando aquellas representaciones que los caracterizan como violentos y anómicos (Bonvillani, 2019), al poner en juego imágenes vinculadas con lo delicado, lo sutil y lo pacificado, presentes en el simbolismo del humo del incienso.

Como una forma de sintetizar y poner nombre a la experiencia de participar de esta intervención artística, aparece la categoría nativa «mística», en tanto se la connota con un tono emocional ligado a una alquimia compleja producto de sensaciones encontradas. Como se ha desarrollado en trabajos anteriores (Bonvillani y Roldán, 2017), la tensión entre estados anímicos vinculados a la alegría y a la tristeza caracteriza el tono emocional de la MDG, teniendo en cuenta que la algarabía y la celebración de los cuerpos en la calle contrastan con las afectaciones emocionales que se encuentran irreparablemente en el trasfondo de las demandas que motivan la propia manifestación, como son la denuncia y el reclamo por el hostigamiento cotidiano que puede llegar al extremo de la muerte producida por la bala policial. En este marco, toda intervención artística debe lidiar con emocionalidades diversas y, a veces, contradictorias: la búsqueda de la celebración de la vida en paz y armonía contrarresta la bronca y la ira que provoca la injusticia, y cobra importancia particular para aquellos que más sufrieron la pérdida de los jóvenes: sus familiares.

La «intervención de los sahúmos» pone en escena ambos sentidos, ya que hace posible celebrar las vidas que fueron arrebatadas por la violencia policial en señal de conmemoración, así como purificar sus almas, capitalizando el sentido del ritual humeante que impregna el aire, al hacerlo más agradable, menos persecutorio.

12 En un hecho inédito en democracia, en agosto de 2017 la Policía de Córdoba allanó varios locales de organizaciones sociales y políticas, e incluso emitió mensajes intimidatorios a sus integrantes tendientes a criminalizar la protesta social. Fuente: Centro de Estudios Legales y Sociales, 31/8/17. Disponible en: https://www.cels.org.ar/ 
Es posible imaginar que esta ceremonia viene a reparar simbólicamente las vivencias de dolor, temor y vergüenza que sufren día a día los miles de jóvenes pobres perseguidos y violentados en esas calles del centro de la ciudad de Córdoba, en las cuales por unos instantes se respira un aire distinto, de paz:

Vino muy bien [...] generó como una muy buena energía a la Coordinadora de Familiares ${ }^{13}$, porque esa mística de hacerlo en medio de la marcha, pero también el celebrar las vidas de los pibes que se fueron y de purificarlos para que [hace un gesto de apretar la mano y la boca], aunque no haya justicia, no sé, al menos que haya un poco de paz [afloja el gesto y la mirada] (Lucrecia, participante de la Comisión Artística, entrevista del 19/9/18).

Otras vertientes del simbolismo que caracterizó la «intervención de los sahúmos» se vincula con cierto halo de misterio, y vuelve difícil analizar las sensaciones y comprensiones que produjo en cada participante, así como en los demás manifestantes. En este sentido, no hace otra cosa que aludir a la misma dimensión simbólica del arte, en tanto se refiere a la presencia de lo simbólico como aquello que escapa a una aprehensión conceptual unívoca, como la posibilidad de una producción incesante de sentidos que no se agota en una relación lineal entre significante y significado. Siguiendo a Escobar (2021), los símbolos presentes en el arte «muestran más mediante lo que encubren que a través de lo que declaran», por lo que resulta cauto desconfiar de cualquier interpretación que pretenda imponerse como la única posible (p. 13).

En palabras de la creadora de esta intervención, el simbolismo del humo aparece ligado ontológicamente a la presencia de lo universal o trascendental, en la trama interconectada de una multiplicidad de sentidos evocados por cada uno de los elementos simbólicos, tales como el fuego, el humo, el agua, la tierra, los dioses:

cuando vos prendés estos turíbulos ponés ahí todos tus deseos y el humo lo que hace es que se los lleva y los escuchan los dioses. Esa es la imagen [...] era como elevar las plegarias y limpiar, limpiar toda esa mala energía que había quedado de la anterior (Zoe, coordinadora de la «intervención de los sahúmos», entrevista del 26/9/18).

Solares Altamirano (2011) señala que el símbolo alude a una realidad difícil de presentar, y que por lo tanto solo puede ser referida de forma simbólica. Su comprensión Ilama a una hermenéutica, es decir, a una interpretación no únicamente intelectual sino afectiva y emocional, una 
apertura, en tanto remite a una multiplicidad de sentidos, imposibles de agotarse en un único significante.

En ese juego de apertura de sentidos, entre los propios jóvenes participantes se le atribuye un papel fundamental a la imagen. Destaca su potencial para interpelar en forma directa y producir una fuerte movilización emocional dada la contundencia del mensaje:

Las imágenes, tanto fotos, pegatinas como la imagen de la intervención directa ahí, la de las antorchas, o los sahúmos o las balas $^{14}$, [son] impactantes y que por más que la[s] saquen al día siguiente, nada, comunica directo [...] hay un impacto, hay algo que nos pega. Van ahí a los ojos directamente, no es que tenés que escucharla y digerirla, sino que está ahí y te queda en los ojos. Si te pegó, te pegó y si no te pegó, bueno, todo bien. Pero te va directo, te entra directo (Juana, participante de la Comisión Artística, entrevista del 29/11/18).

La forma de expresión que se pone en juego en la «intervención de los sahúmos» aparece asociada a una necesidad de correrse de una posición racionalista y logocéntrica, ya que los recursos de los cuales se vale (imágenes, olores, sonidos, movimientos corporales) escapan al régimen del discurso y habilitan experiencias e interpretaciones diversas. Incluso dejan zonas vacantes de sentido, indescifrables desde una homogeneidad dada de antemano:

Viste, por ejemplo, que suelen decir que hay que hablar para expresar el arte, para que se entienda, y yo lo había pensado diciendo «capaz que no hace falta hablarlo» [...] Como que un poco de tierra o de humo ya demuestra un montón de las cosas que podemos decir (Valentín, integrante de una banda musical que tocó en la manifestación, entrevista del 2/11/18).

Y para mí como que se plantean, al no ser tan clara esta imagen, vos decís «¿qué hacen unas pibas danzando con humo?», pero hay algo que se entiende desde otro lado, que no se entiende tan racionalmente, pero que se entiende (Zoe, coordinadora de la «intervención de los sahúmos», entrevista del 26/9/18).

Según Rancière (2010), disenso significa una organización de lo sensible en la que no hay un régimen único de representación y de interpretación que imponga a todos su evidencia. Por eso toda situación es susceptible de ser reconfigurada bajo otro régimen de percepción y significación. De esta manera, la política del arte modifica el territorio de lo posible y la 


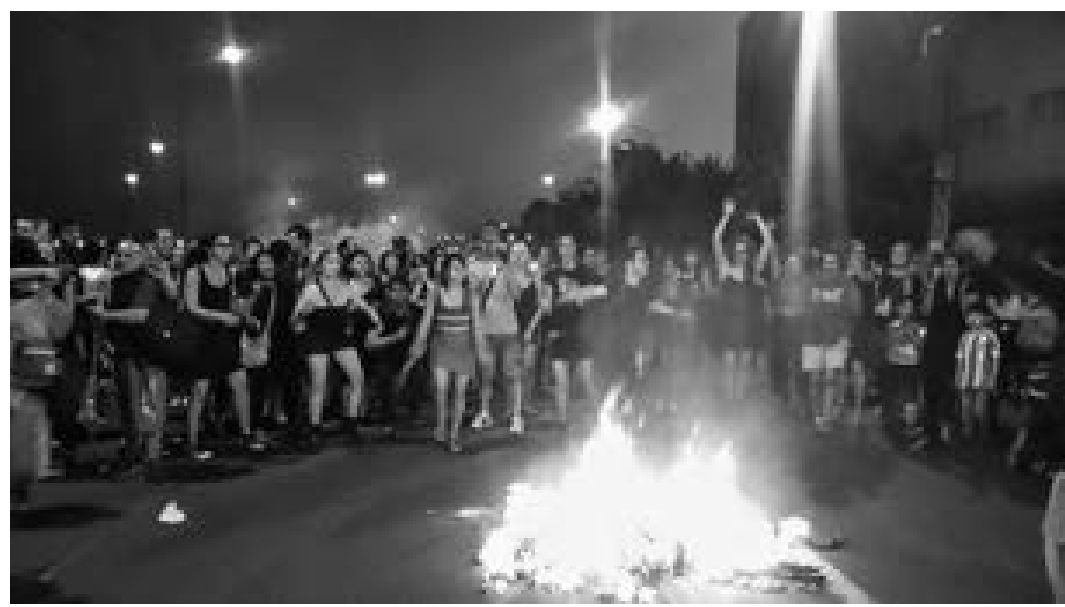

FOTOGRAFÍA 2

Fuente: elaboración propia

distribución de las capacidades e incapacidades, reivindicando la igualdad de inteligencias. En el contexto de la MDG, el arte aparece mencionado reiteradas veces como un lenguaje que iguala, capaz de producir el entendimiento de y entre todos. Al respecto destacan las entrevistadas:

la palabra tiene intenciones diferentes en quién la dice y quién la recibe, como que genera un cortocircuito. En lo artístico es menos probable que pase eso. Es otra manera de expresar las cosas, donde nos entendemos todos (Lucrecia, participante de la Comisión Artística, entrevista del 19/9/18).

Sí, me reconozco ahí y entiendo lo que está queriendo decir, y siento que me está pasando algo similar, y lo puedo canalizar de esta forma y nos estamos entendiendo (Julieta, participante de la Comisión Artística, entrevista del 26/9/18).

Así, el arte se presenta como un conjunto de prácticas que, al dar lugar a la creatividad, la espontaneidad y la múltiple producción de sentidos, habilitan una democratización del entendimiento, al no constituir un dominio exclusivo para quienes comparten un determinado saber teórico-político o técnico-práctico. En este sentido, al régimen estético del arte le subyace un modelo de eficacia que supone la suspensión de toda relación directa y lineal entre la producción de las formas por parte del artista y la producción de un efecto determinado en los espectadores (Rancière, 2010).

Al final del recorrido de la decimoprimera MDG se realizó la quema de los turíbulos, acción que obedeció a la necesidad de darle un cierre a la intervención. 
Bien en lo material, en lo concreto, ¿qué es lo que se hace?, porque después lo terminás guardando, se termina rompiendo y eso como universalmente hay algo ahí como que no cierra y el fuego siempre es como lo más sagrado, jya está!, desaparece (Zoe, coordinadora de la «intervención de los sahúmos», entrevista del 26/9/18).

El uso del fuego que hizo arder en llamas al objeto sahumante reviste un doble carácter. Por un lado, permite la extinción material del objeto, pero a la vez tiene un alto potencial de significación simbólica, ya que, tras descomponerse, dicho objeto desaparece en el plano de la representación material y es transformado en energía que se eleva en forma de humo y en polvo que se integra a la tierra.

El simbolismo asociado al fuego está presente en la historia de la humanidad. Se lo considera un agente canónico de transformación, mediador entre formas de destrucción y de creación, de cierres y aperturas, de muerte y renacimiento (Cirlot, 1997). El uso del fuego para lograr que algo o alguien deje de existir en lo físico, se asocia a la pretensión de que en su lugar venga algo nuevo, representando en este acto intensos procesos de lucha, organización y movilización para la «creación» de un nuevo orden, en el caso que nos convoca, más justo e igualitario.

En consonancia con lo anterior, la quema de turíbulos constituyó para quienes la emprendieron un acto ritual sagrado, en tanto irrumpió en la arena pública torciendo las dimensiones de tiempo y espacio, a través de una práctica disruptiva desarrollada por fuera de los acuerdos establecidos al interior de la mesa organizadora, lo cual generó una gran tensión especialmente en los responsables de la seguridad ${ }^{15}$ de la MDG, quienes interpretaron esta trasgresión como una falta de respeto a los acuerdos colectivos previamente asumidos (registro etnográfico de reunión de evaluación, 30/11/2017).

Además de la peligrosidad propia del uso del fuego, en el caso que nos ocupa debemos considerar que la dinámica callejera de la MDG representa cierta rutina en el manejo del tiempo: sus organizadores controlan minuciosamente el horario de salida y el de llegada, y el ritmo de marcha que debe ser respetado para su cumplimiento. En cada edición, la puesta en acto de las intervenciones artísticas supone detener

15 Dentro de las comisiones a partir de las cuales se organiza la logística de la MDG, la de seguridad se ocupa de cuidar la integridad física de los manifestantes, teniendo en cuenta diversas situaciones que pueden presentarse en el espacio de la calle cuando se movilizan tantas personas, desde conflictos entre agrupaciones y participantes, hasta tensión con transeúntes o la propia Policía. Durante las reuniones previas se establecen acuerdos entre los presentes, como el orden en que se ubicarán los grupos en las columnas o el tiempo con que contarán las intervenciones artísticas para su realización. 
el flujo de las columnas, lo cual expone a los manifestantes y ralentiza la propia dinámica de la marcha. Por ende, la tensión entre responsables de la seguridad de la MDG y artistas que realizan las intervenciones es un punto sensible que se ve amplificado si tenemos en cuenta el grado de institucionalización de una acción colectiva de protesta que se realiza desde hace tantos años.

En este marco, las intervenciones artísticas del tipo aquí analizado constituyen una ruptura en el devenir previsto de la marcha. La experiencia de lo sagrado comienza ante esas situaciones que escapan y transfiguran lo dado natural y cotidianamente: «esa energía desbordante y extraña que puede ser adversa o propicia, ese impulso que perturba ciertos momentos o lugares, seres o cosas, los arranca de su banal facticidad y los enfrenta al umbral del sentido» (Escobar, 2021 p. 280).

En la literatura antropológica, el ritual aparece como una ruptura de la cotidianeidad. Asún et al. (2020) entienden a las acciones de protesta social como una forma de ritual colectivo, es decir, como un conjunto de conductas de alto contenido simbólico que habitualmente se realizan repitiendo pautas ya ensayadas. Siguiendo a Rancière (2016), es particularmente la presencia del arte en el marco de la acción colectiva lo que habilita la subversión del tiempo, a través de un acto disruptivo que inventa una nueva temporalidad que pone en jaque lo programado, lo que de alguna forma se ha instituido. En este sentido, las expresiones que se apoyan en la creatividad y la espontaneidad se resisten a las lógicas reproductivas que, paradojalmente, pueden cristalizarse en acciones que se definen por su condición disruptiva y contestataria.

\section{Impacto político de la intervención artística}

Las intervenciones artísticas, al ser escenificadas en el espacio público, pueden pensarse como un texto estético colectivo que pretende construir un mensaje dirigido a ciertos sectores sociales o a la sociedad en su conjunto (Scribano y Cabral, 2009). En este sentido, el arte persigue la impugnación de las formas instituidas y aloja otras lecturas de realidad posible, poniendo en visibilidad lo no dicho, lo no visto. De este modo, como ya se ha planteado con antelación, las intervenciones artísticas que los jóvenes despliegan en la MDG ofrecen una oportunidad alternativa a los lenguajes y formas políticas convencionales de generar reflexión y cuestionamiento sobre situaciones de persecución, hostigamiento, tortura y asesinato ejecutadas por las fuerzas policiales del estado cordobés. Este trabajo político de impugnación y creación de sentidos contrahegemónicos que opera el activismo artístico en la MDG ha sido reportado en producciones anteriores (Bonvillani, 2015b). 
En ese marco, el aporte diferencial que ha realizado este trabajo radica en avanzar respecto de una de las cuestiones centrales en el campo de estudios que cruzan el arte y la política, como es el problema de la representación.

En la sección anterior del artículo, se describen los modos como la creadora de la intervención artística aquí analizada y los jóvenes que acompañaron su realización reivindican que dicha intervención no apele a referentes empíricos o materiales, cuya interpretación de manera lineal y unívoca clausurara la diversidad de sentidos que pudieran movilizarse.

En el planteo de Rancière (2010) justamente esta es la operación que permite orientar la práctica artística hacia un efecto político emancipatorio: el tomar distancia del régimen representativo de las imágenes sujeto a cierta continuidad mecánica entre la intencionalidad del autor y los efectos que provoca en la audiencia.

La crítica del filósofo se dirige entonces a aquellas formas de visibilidad ligadas a la representación y la mimesis, que no hacen más que reproducir y ontologizar la realidad que representan $y$, con ello, generan un efecto de normalización de la distribución policial de lo sensible. Esta mirada, que toma distancia de la forma de entender el arte como representación, parece inspirar las modalidades de encarnar el arte en la intervención artística de los sahúmos. En palabras de una activista:

Plantear el objetivo distinto: no reproducir algo, como que estás poniendo todas tus energías en crear algo (Zoe, coordinadora de la «intervención de los sahúmos», entrevista del 26/9/18).

La construcción participativa de la intervención y la actitud de apertura hacia una multivocidad de sentidos, mediante la inclusión de elementos con una fuerte carga simbólica, trascienden el efecto de visibilidad ligado a la mera representación:

Está bueno porque es otra forma de hacer ver el significado de la marcha. No solamente el ir marchando en sí, sino que le da como un toque nuevo, expresa algo y a la vez deja que cada uno le dé su interpretación (registro de conversación en marcha, 17/11/17).

La impugnación de la lógica representacional en el arte, dado su carácter ontologizador $y$, por ende, reductor de las diferencias y las particularidades en las formas múltiples de interpretar el mensaje de la obra, opera de un modo análogo en el plano de la representación de la política en un sistema representativo-liberal: el «representante» (político profesional) hegemoniza todos los sentidos posibles en el campo a ser representado, y se erige en un único significante representacional: 
Lo que tiene la marcha es que se quiere visibilizar algo, que se visibiliza, pero ¿desde dónde? o ¿hacia quién? Yo, como hacedora, pienso que no va a venir ningún legislador a darme la solución, a ningún humano (Zoe, coordinadora de la «intervención de los sahúmos», entrevista del 26/9/18).

La cuestión del impacto político de las acciones artísticas ha sido uno de los emergentes del proceso de investigación que origina este artículo y se plantea como pregunta para el propio colectivo que organiza la MDG, frente al contraste entre la nutrida convocatoria de estas acciones y un marcado recrudecimiento de la política punitiva del Estado provincial (registro etnográfico de la mesa organizadora, 29/9/17). En otras palabras, la inquietud que parece latir y que queda disponible para futuras indagaciones es si el efecto expresivo, incluso catártico, de este repertorio de estrategias artísticas alcanza para frenar la ferocidad represiva del aparato estatal.

\section{A modo de cierre}

En este trabajo nos hemos preguntado por el alcance de lo artístico como lugar de resistencia, de crítica y oposición, tomando distancia del presunto riesgo de neutralizar y estetizar la lucha a través de una concepción «romántica» del arte, o bien reducir su potencialidad a una idea «utilitaria».

Desde esta posición, lo que está en juego es una idea de la política como un nuevo modo de disposición entre los cuerpos, el corte o ruptura de una unidad espacio-temporal, en la que existe una relación promiscua e indeterminada entre las prácticas políticas y las prácticas artísticas (Rancière, 2016).

Desde estos supuestos se ha analizado el potencial político de una intervención artística desarrollada en el marco de una acción colectiva antirrepresiva, la cual se destaca por el gran despliegue de cuerpos jóvenes en el escenario de la calle, la profundidad de los sentidos desplegados y el tono emocional ligado a una alquimia compleja entre sensaciones que involucran duelo, celebración, paz y armonía, y que intentan ser un antídoto frente a la ira que provoca la injusticia de las muertes y las persecuciones de los jóvenes de sectores populares de Córdoba.

Como se ha argumentado, esta acción expresiva constituye una apuesta que reivindica la multiplicidad de modos de expresión, sustrayendo su primacía a lo meramente discursivo, integrando otros registros ligados a lo sensorial-corporal y lo imaginativo, para reivindicar un lenguaje integral e inclusivo. 
Esta es una de las ocasiones en las cuales el lenguaje hablado o escrito no alcanza como vehículo de expresión, y se vuelve necesario apelar a otros modos de canalización de impresiones y sentidos, en los que el cuerpo cobra relevancia y aparece como locus de politización (Bonvillani y Roldán, 2017). El arte se presenta entonces como posibilidad que amplía los márgenes de expresión, en tanto integra distintos modos de hacerse presente en la arena pública, involucrando canales que exceden lo discursivo y ponen en juego, además de una dimensión cognitiva y reflexiva, un fuerte componente afectivo-emocional que da lugar a un modo distinto de estar/habitar el espacio.

Esta manifestación de activismo artístico es capaz de rebasar los límites de significación que impone la racionalidad discursiva y abre a una multiplicidad de sentidos, con lo que logra un efecto de visibilidad de una problemática social, pero la trasciende en términos de mera reproducción de la realidad. Junto con Longoni (2010) consideramos que esta cuestión remite al problema de la representación, tanto en el plano del arte como en el de la política, derivado de la crisis de legitimidad de las formas tradicionales que ambos campos han asumido.

Finalmente, se quiere realizar el siguiente apunte. El carácter espontáneo y creativo de la intervención artística analizada en este trabajo entra en tensión con las reglas y acuerdos establecidos entre los grupos que participan de la planificación de la marcha de protesta, poniendo de manifiesto que se trata de dos lógicas diferentes. Si la expresión artística parece impugnar los límites de lo establecido, instituyendo por ejemplo una temporalidad dislocante de lo previsto, la dimensión organizativa de la manifestación debe cuidar aspectos atinentes a la operatividad y factibilidad de la propia acción en la calle, incluso en lo referido a la seguridad de los que marchan. Paradojalmente, esta tensión se produce al interior de una práctica política que se define como disruptiva, pero que debe lidiar con una faceta organizativa estabilizada en un tiempo y espacio determinado.

\section{Contribución de autoría}

Andrea Bonvillani es responsable de la coordinación general de la investigación que origina este artículo, el análisis de datos y su redacción. Agostina Latimori realizó el trabajo de campo y participó en la redacción del artículo.

\section{Fuente de financiamiento}

Subsidio de la Secretaría de Ciencia y Tecnología de la Universidad Nacional de Córdoba, otorgado al Proyecto Consolidar (2018-2021) 
denominado «Militancias juveniles cordobesas» (Resolución Secyt, UNC, 455/18).

\section{Potenciales conflictos de interés}

Ninguno. 


\section{REFERENCIAS BIBLIOGRÁFICAS}

Asún, R., Navarro, K. y Tintaya Orihuela, M. (2020). ¿Por qué surgen los estallidos sociales? Emociones, redes interpersonales, rituales y participación en protestas. Última década, 28(54), pp. 5-40. Recuperado de https://dx.doi.org/10.4067/S0718-22362020000200005.

Bonvillani, A. (2015a). El Código de Faltas de la provincia de Córdoba (Argentina) como dispositivo de poder. La construcción de la seguridad a partir de la equivalencia simbólica «joven pobre=peligroso». Controversias y Concurrencias Latinoamericanas, 7(11), pp. 81-101. Recuperado de http:// ojs.sociologia-alas.org/index.php/CyC/issue/view/12

Bonvillani, A. (2015b). Callejeando la alegría... y también el bajón. Etnografía colectiva de la Marcha de la Gorra. Córdoba: Encuentro Grupo Editor.

Bonvillani, A. (2018). Etnografía colectiva de eventos: la cronotopía paradojal de la Marcha de la Gorra (Córdoba, Argentina). De Prácticas y Discursos, 7(9), pp. 161-184. Recuperado de http://dx.doi.org/10.30972/ dpd.792806

Bonvillani, A. (2019). Negros de alma. Imaginarios racializados y juvenicidio en la Córdoba de las campanas. Tabula Rasa, 31, pp. 325-346. Recuperado de https://revistas.unicolmayor.edu.co/index.php/tabularasa/article/ view/1010

Bonvillani, A. (2020a). La acción colectiva juvenil como experiencia de subjetivación política. En G. Castro (Comp.), Juventudes en movimiento: avatares y desafíos (pp. 187-206). Buenos Aires: Teseo.

Bonvillani, A. (2020b). Todos los días morir un poco. Sentidos subjetivos de juventudes alcanzadas por la violencia policial. JOVENes. Revista de Estudios Sobre Juventud, 35, pp. 77-104.

Bonvillani, A. y Roldán, M. (2017). Politización de los cuerpos juveniles: la Marcha de la Gorra como performance multitudinaria. Aposta. Revista de Ciencias Sociales, 74, pp. 165-203. Recuperado de http://apostadigital. com/revistav3/hemeroteca/autora.pdf

Borges, A. (2004). Tempo de Brasília: Etnografando lugares eventos da política. Rio de Janeiro: Relume Dumará.

Cirlot, J. E. (1997). Diccionario de símbolos. Barcelona: Ediciones Siruela.

Diani, M. (2015). Revisando el concepto de movimiento social. Encrucijadas, 9, pp. 1-16. Recuperado de https://dialnet.unirioja.es/ servlet/articulo?codigo $=5171769$

Escobar, T. (2021). Contestaciones: Arte y política desde América Latina. Buenos Aires: CLACSO. 
Gabrieloni, M. y Bonvillani, A. (2015). Luchar desde la alegría: la politicidad en las prácticas murgueras. En A. Bonvillani (Ed.), Callejeando la alegría... y también el bajón (pp. 151-176). Córdoba: Encuentro Grupo Editor.

Grau-Dieckmann, P. (2003). Los perfumes en el cristianismo. Mirabilia, 3, pp. 75-92.

Guber, R. (2001). La etnografía. Método, campo y reflexividad. Bogotá: Grupo Editorial.

Job, S. (2018). Del Estado policial al Estado dron. Formas de gobernanza securitaria en tiempos de racionalidad neoliberal. En M. Díaz de Landa (Comp.), Manual de Sociología Jurídica. Tomo II (pp. 137). Córdoba: Universidad Nacional de Córdoba.

Longoni, A. (2010). Arte y política: políticas visuales del movimiento de derechos humanos desde la última dictadura: fotos, siluetas y escraches. Aletheia, 1, pp. 1-23. Recuperado de http://sedici.unlp.edu.ar/bitstream/ handle/10915/69047/Documento_completo.pdf?sequence=1

Ortega, V. (2015). El artivismo como acción estratégica de nuevas narrativas artístico-políticas. Calle14, 10(15), pp. 100-111. Recuperado de https://www.redalyc.org/pdf/2790/279038948008.pdf

Lerchundi, M. y Bonvillani, A. (2016). Del Código de Faltas al Código de Convivencia Ciudadana, algunas diferencias a la luz de la Marcha de la Gorra (Córdoba, Argentina). Cuadernos del CIESAL, 13(15), pp. 83-109. Recuperado de http://hdl.handle.net/2133/6978

Maxwell, J. A. (1996): Qualitative research design. An interpretative approach. London: Sage Publications.

Rancière, J. (2000). Política, identificación, subjetivación. En B. Arditi (Ed.), El reverso de la diferencia. Caracas: Nueva Sociedad.

Rancière, J. (2002). La división de lo sensible. Estética y política. Salamanca: Centro de Arte de Salamanca.

Rancière, J. (2005). Sobre políticas estéticas. Barcelona: Universidad Autónoma de Barcelona.

Rancière, J. (2007): La distorsión: política y policía. En El desacuerdo. Política y filosofía. Buenos Aires: Nueva Visión.

Rancière, J. (2010). El espectador emancipado. Buenos Aires: Ediciones Manantial. 
Rancière, J. (2016). La extrema derecha está volviendo a ser exitosa en su evocación de símbolos identitarios muy primitivos. Entrevista realizada por Federico Galende. The Clinic. Recuperado de https://www.theclinic. $\mathrm{cl} / 2016 / 12 / 04 / j a c q u e s-r a n c i e r e-l a-e x t r e m a-d e r e c h a-e s t a-v o l v i e n d o-a-$ ser-exitosa-en-su-evocacion-de-simbolos-identitarios-muy-primitivos/?f bclid=IwAR1 sIVOAkMfNJCGkcXXkkvdiqRG9N6JdAW7wie1HTryhXv2H5w 8DGARDzR0

Scribano, A. y Cabral, X. (2009). Política de las expresiones heterodoxas: el conflicto social en los escenarios de las crisis argentinas. Convergencia, 16(51), pp. 129-155. Recuperado de http://www.scielo.org.mx/pdf/ conver/v16n51/v16n51a6.pdf

Solares Altamirano, B. (2011). Gilbert Durand, imagen y símbolo o hacia un nuevo espíritu antropológico. Revista Mexicana de Ciencias Políticas y Sociales, 56(211), pp. 13-24.

Strauss, A. y Corbin, J. (2002). Bases de la investigación cualitativa. Técnicas y procedimientos para desarrollar la teoría fundamentada. Medellín: Editorial de la Universidad de Antioquia.

Svampa, M. (2007) Movimientos sociales y escenario político: las nuevas inflexiones del paradigma neoliberal en América Latina. Versión presentada en la VI Cumbre del Parlamento Latinoamericano, Caracas, 31 de julio-4 de agosto de 2007. Recuperado de http://maristellasvampa.net/ archivos/ensayo38.pdf

Valles, M. (2007). Entrevistas cualitativas. Madrid: Centro de Investigaciones Sociológicas.

Vommaro, P (2015). Juventudes y políticas en la Argentina y en América Latina: tendencias, conflictos y desafíos. Buenos Aires: CLACSO y Grupo Editor Universitario. 